\title{
Evaluation of analgesic activity of levofloxacin in adult albino rats
}

\author{
Prasanna Kumari S., Latha K.*, Meeradevi A.
}

Department of Pharmacology, GMC-ESI Hospital, Coimbatore, Tamil Nadu, India

\author{
Received: 05 November 2020 \\ Revised: 08 December 2020 \\ Accepted: 09 December 2020 \\ *Correspondence: \\ Dr. Latha K, \\ Email: drklatha@gmail.com
}

Copyright: (C) the author(s), publisher and licensee Medip Academy. This is an open-access article distributed under the terms of the Creative Commons Attribution Non-Commercial License, which permits unrestricted non-commercial use, distribution, and reproduction in any medium, provided the original work is properly cited.

\begin{abstract}
Background: Levofloxacin is a fluorinated quinolone antimicrobial used in the treatment of various bacterial infections and was active against both gram positive and gram negative bacteria. Levofloxacin is an optically active isomer of ofloxacin. Apart from its antibacterial action, it also exhibit antinociceptive properties. This study was conducted with the aim to evaluate the analgesic activity of Levofloxacin in albino rat in comparison with aspirin.

Methods: Thirty adult albino rats weighing 150-250 gm were obtained from central animal house. The animals were divided into five groups of six animals each. Group I served as control received normal feed and water. Group II served as standard received tablet aspirin $100 \mathrm{mg} / \mathrm{kg}$ (oral) and Group III, IV, V served as test T1, T2, T3 and received tablet levofloxacin $10 \mathrm{mg} / \mathrm{kg}, 20 \mathrm{mg} / \mathrm{kg}$ and $40 \mathrm{mg} / \mathrm{kg}$ (oral), respectively. The analgesic effect of levofloxacin was evaluated using Eddy's hot plate and tail flick methods and compared with standard analgesic aspirin. The values obtained were expressed as mean \pm SD. Statistical analysis of difference between groups were carried out using one-way analysis of variance (ANOVA). Probability $\mathrm{p}<0.05$ was taken as the level of statistical significance.

Results: Levofloxacin at $40 \mathrm{mg} / \mathrm{kg}$ showed statistically $(\mathrm{p}<0.05)$ elevation in pain threshold and a higher antinociceptive activity in comparison to control and standard groups.

Conclusions: In the present study, levofloxacin has showed promising results as an analgesic when compared to the control and standard groups. It may be a lead compound for identifying newer adjuvant analgesic agents.
\end{abstract}

Keywords: Analgesic activity, Levofloxacin, Tail flick method, Eddy’s hot plate method

\section{INTRODUCTION}

According to the International Association for the Study of Pain (IASP), Pain is defined as "an unpleasant sensory and emotional experience associated with actual or potential tissue damage". ${ }^{1}$ Over the course of human history pain has been treated by psychological technique, physical method (surgical intervention, electrical stimulant, pressure, cold, heat, counter irritant, acupuncture) and by drugs. ${ }^{2}$ Pain itself is not a disease; it is far the most common medical complaint.

Analgeisc medications are the first line of treatment in pain management. The control of pain is one of the most important uses to which drugs are put. In recent decades, commonly used drugs for pain relief is morphine and diclofenac. These opioids and non-steroidal antiinflammatory drugs (NSAID's) can only relieve $50 \%$ of pain, in about $30 \%$ of the patients. ${ }^{3}$ In addition, many of these drugs cause serious adverse effects. Opiates causes physical dependency, tolerance and addiction while NSAIDs usually cause gastrointestinal disorders. 4 In spite of vast number of drugs with analgesic property, search for new analgesics with better efficacy and minimal adverse effect are continuing throughout the world.

Treatment of certain antibiotic can decrease the pain. Levofloxacin is a fluorinated quinolone antimicrobial used in the treatment of various bacterial infections and was active against both Gram positive and Gram negative 
bacteria. Levofloxacin is an optically active isomer of ofloxacin.

Fluoroquinolones exhibit both central nervous system (CNS) stimulant and depressant effects by gammaamminobutric acid (GABA-A) receptor inhibition. Levofloxacin inhibit the GABA-A response in a competitive and voltage independent manner, which can be responsible for its analgesic effect. There is also evidence indicating that, depressive action on calcium current may be involved in antinociceptive effect of levofloxacin.

Aspirin, a NSAID, acts by blocking the enzyme cyclooxygenase, which catalyses the biosynthesis of prostaglandins and thromboxane from arachidonic acid.

\section{METHODS}

The animal study was a cross sectional, observational study, conducted in Institute of Pharmacology, Madurai Medical college, Madurai after obtaining due approval from Institutional Animal Ethics Committee. The was conducted in the month of May 2018.The study followed the principles of Committee for the purpose of control and supervision of experiments on animals (CPCSEA) and utmost care was taken while handling the animals and adequate care was provided to them during and after experimentation as per the "Guidelines for the care and use of laboratory animals."

30 adult albino rats weighing 150-250 gm were obtained from central animal house, Madurai Medical College, Madurai. They were housed in cages in standard laboratory conditions with natural light and dark cycle and at room temperature. The animals had free access to food and water ad libitum.

The animals were divided into five groups of six (6) animals each:

Group1 served as control, received normal feed and water, Group II served as standard, received tablet aspirin 100 $\mathrm{mg} / \mathrm{kg}$ (oral), Group III, served as test group T1, received tablet levofloxacin $10 \mathrm{mg} / \mathrm{kg}$ (oral), Group IV, served as test group T2, received tablet levofloxacin $20 \mathrm{mg} / \mathrm{kg}$ (oral), Group V, served as test group T3, received tablet levofloxacin $40 \mathrm{mg} / \mathrm{kg}$ (oral).

All drug solutions were freshly prepared in double distilled water at room temperature and were given orally.

\section{Methods for evaluation of analgesic effect}

For assessing the analgesic activity, two thermal methods were used, Tail flick method, Eddy's hot plate method., 5

\section{Analgesiometer by tail flick method using radiant heat from electric sources}

Tail flick latencies (reaction time) of the animal were assessed by the analgesiometer. The strength of the current passing through the naked nichrome wire was kept constant at 5 amps. The distance between the heat source and tail skin was $1.5 \mathrm{~cm}$. The site of application of the radiant heat in the tail was maintained at $2.5 \mathrm{~cm}$, measured from the root of the tail. The time taken by the animal to withdraw (flick) its tail from the hot wire was noted and taken as the 'reaction time. This tail flicking was considered as the end point of this test and time taken for tail flicking was measured for each rat. The cut-off time of 10 seconds was planned to avoid any tissue damage. After drug administration, the reaction time of each rat was recorded at 30 minutes, 1, 2, 3 hours. The mean of the observed values was considered for statistical analysis.

\section{Thermal stimulus by eddy's hot plate method}

The rats were placed on a hot plate, one by one, which was maintained at a temperature of $55 \pm 0.5^{\circ} \mathrm{C}$ throughout the test. A cut-off period of 15 seconds was considered as maximal latency to avoid injury to the paws. The time taken by the animals to lick the hind paw or jump away was taken as the reaction time and measured. The drug was administered, the reaction time for each rats was recorded at 30 minutes, 1 hour, 2 hour, 3 hours. The mean of the observed values was considered for statistical analysis.

\section{Statistical methods}

The values obtained were expressed as mean \pm SD. Statistical analysis of differences between groups was carried out using one-way analysis of variance (ANOVA). Probability $\mathrm{p}<0.05$ was taken as the level of statistical significance.

\section{RESULTS}

In Tail flick test, the reaction time of the rats were recorded at 30 minutes, 1, 2, 3 hours, after drug administration the results obtained were expressed as mean $\pm \mathrm{SD}$.

Levofloxacin showed statistically $(\mathrm{p}<0.05)$ elevation in pain threshold in comparison to control as represented in table 1 , figure 1 The results also demonstrated that analgesic activity produced by levofloxacin was compared to that of standard group that received aspirin.

In hot-plate method, the reaction time was recorded at 30 minutes, 1 hour, 2 hour, 3 hours after the drug administration, results obtained were expressed as mean \pm SD. 
Levofloxacin showed statistically significant $(\mathrm{p}<0.05)$ elevation in pain threshold when compared to control, as represented in table 2 , figure 2 . The results also demonstrated that analgesic activity produced by levofloxacin was compared to that of standard group that received aspirin.

Table 1: Analgesic effect of levofloxacin by tail flick method.

\begin{tabular}{|lllll|}
\hline Groups & $\mathbf{3 0} \mathbf{m i n}$ & $\mathbf{1 ~ h r}(\mathbf{6 0} \mathbf{m i n})$ & $\mathbf{2 ~ h r}(\mathbf{9 0} \mathbf{m i n})$ & $\mathbf{3 ~ h r}(\mathbf{1 2 0} \mathbf{m i n})$ \\
\hline Group I & $5.01 \pm 0.46$ & $5.34 \pm 0.56$ & $5.40 \pm 0.38$ & $5.31 \pm 0.38$ \\
\hline Group II & $5.72 \pm 0.20$ & $7.15 \pm 0.55^{*}$ & $9.30 \pm 0.76^{*}$ & $8.60 \pm 0.73^{*}$ \\
\hline Group III & $5.22 \pm 0.30$ & $5.73 \pm 0.37$ & $7.83 \pm 0.26^{*}$ & $7.31 \pm 0.41^{*}$ \\
\hline Group IV & $5.31 \pm 0.32$ & $5.80 \pm 0.26^{*}$ & $6.84 \pm 0.30^{*}$ & $7.41 \pm 0.34^{*}$ \\
\hline Group V & $5.56 \pm 0.37$ & $6.83 \pm 0.29^{*}$ & $7.63 \pm 0.26^{*}$ & $7.67 \pm 0.43^{*}$ \\
\hline
\end{tabular}

$* \mathrm{p}<0.05$

Table 2: Analgesic effect of levofloxacin by eddy's hot plate.

\begin{tabular}{|lllll|}
\hline Groups & $\mathbf{3 0} \mathbf{~ m i n}$ & $\mathbf{1 ~ h r}(\mathbf{6 0} \mathbf{m i n})$ & $\mathbf{2} \mathbf{h r}(\mathbf{9 0} \mathbf{m i n})$ & $\mathbf{3} \mathbf{~ h r}(\mathbf{1 2 0} \mathbf{m i n})$ \\
\hline Group I & $4.08 \pm 0.38$ & $3.85 \pm 1.00$ & $3.98 \pm 0.85$ & $4.46 \pm 0.58$ \\
\hline Group II & $4.32 \pm 0.61$ & $5.54 \pm 0.50^{*}$ & $7.70 \pm 0.51^{*}$ & $8.49 \pm 0.51^{*}$ \\
\hline Group III & $4.01 \pm 0.21$ & $4.82 \pm 0.58$ & $5.91 \pm 0.38$ & $6.21 \pm 0.86^{*}$ \\
\hline Group IV & $4.24 \pm 0.51$ & $5.19 \pm 0.48$ & $6.41 \pm 0.34^{*}$ & $7.66 \pm 0.51^{*}$ \\
\hline Group V & $4.24 \pm 0.62$ & $5.49 \pm 0.29^{*}$ & $6.78 \pm 0.20^{*}$ & $7.99 \pm 0.49^{*}$ \\
\hline${ }^{*}<0.05$ & & & & \\
\hline
\end{tabular}

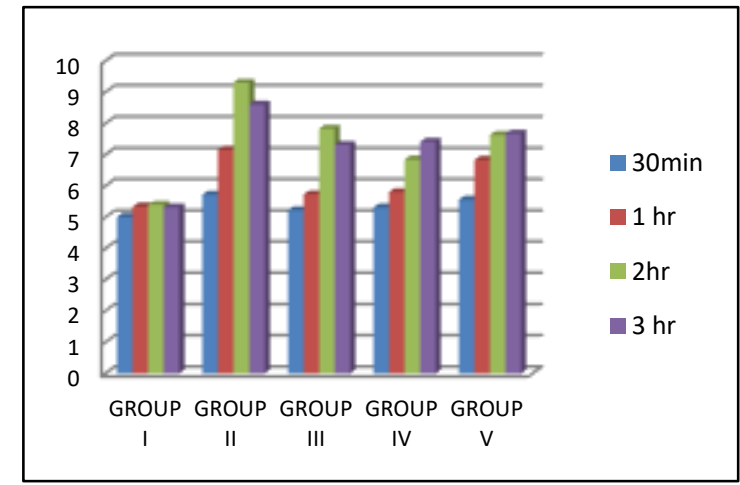

Figure 1: Analgesic activity by Tail flick method.

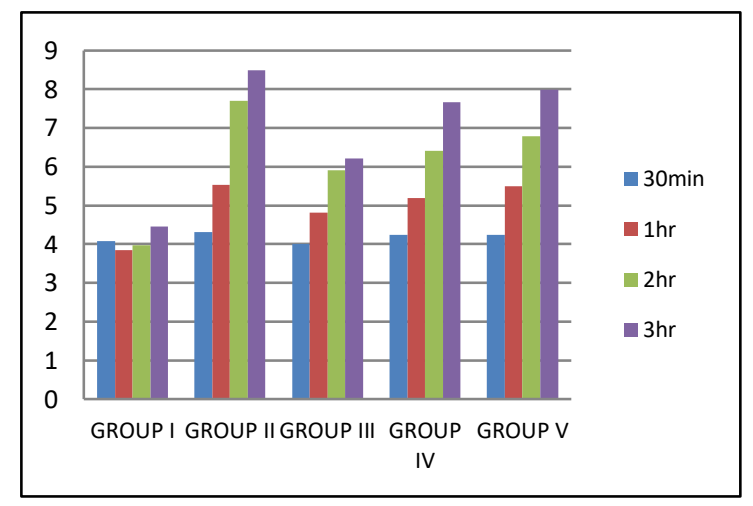

Figure 2: Analgesic activity by Eddy's hot plate method.
The analgesic effect was observed in 1 hour in aspirin and levofloxacin groups; however, it was maintained for 3 hours in both groups.

\section{DISCUSSION}

In this present study Levofloxacin, a fluorinated quinolone anti-microbials was evaluated for its analgesic property in rats by tail flick and Eddy's hot plate methods. The analgesic action was compared with aspirin, which is considered as the standard drug for treating thermally induced pain and was found to be statistically significant. According to Higuchi et al, aspirin has two analgesic effects on pain with central and peripheral actions. ${ }^{7}$

Findings from our study demonstrated that levofloxacin prolonged the reaction time both in tail-flick and hot plate method. Levofloxacin at $40 \mathrm{mg} / \mathrm{kg}$ dose showed a higher antinociceptive activity compared to aspirin at $90 \mathrm{~min}$ and $120 \mathrm{~min}$ in rats which indicates that it has a persistent analgesic action that might be explained due to its long duration of action. ${ }^{8}$

'Pain is a specific sensation with its own peripheral and central mechanisms independent of other five senses'. The tail-flick response is believed to be a spinally mediated reflex and the effectiveness of analgesic agents in the tailflick pain model is highly correlated with relief of human pain perception. This method is also useful in differentiating central opioid-like analgesics from peripheral analgesics. ${ }^{9}$ 
In a study conducted by Woolfe et al tail flick models have conventionally been used to study centrally acting analgesics. ${ }^{10}$ The possible mechanism is that levofloxacin blocks the pain sensation at some central level or by producing the stress effect will be responsible for its analgesic effect (Yildiran et al), a reduction of peripheral nociceptive input to the central nervous system could also reduce central sensitization. ${ }^{11}$

In Eddy's hot plate method, levofloxacin at $40 \mathrm{mg} / \mathrm{kg}$ dose was found have effective antinociceptive activity than at 10 and $20 \mathrm{mg} / \mathrm{kg}$ in rat. Responses such as paw licking and jumping in rats are considered to be supraspinally integrated. A study conducted by Erden et al "levofloxacin showed analgesic activity in acetic acid writing and hot plate test in mice". ${ }^{12}$

Takasuna et al showed that levofloxacin, known to competes with intracellular calcium influx in several biological processes, and is responsible for its analgesic effect in mice. ${ }^{13-15} \mathrm{~N}$-type of calcium channels are critical for pain transduction and modulation. ${ }^{16-18}$ These channels are present at synaptic terminals and dorsal root ganglia cell bodies of the spinal cord. ${ }^{19,20}$ Block of these N-type of channels prevent the release of neurotransmitters like glutamate and substance P. Selective blockers of N-type of calcium channels are powerful analgesics and are being considered of having therapeutic potential in chronic pain management. ${ }^{21}$ Unfortunately, the mechanism by which Levofloxacin inhibit this calcium channel is not yet clear.

Levofloxacin has analgesic properties, could be useful choice of drug for the treatment of patients with painful infections. Levofloxacin $40 \mathrm{mg} / \mathrm{kg}$ had showed a significant analgesic effect in rats. The possible central mechanism for its analgesic effect is reduction of peripheral nociceptive input to the central nervous system that could also reduce central sensitization. It also competes with intracellular calcium by unknown mechanism, that could the possible mechanism for its peripheral analgesic action. Further studies are needed with large number of animals and various other pain models to determine the exact mechanism in depth.

\section{CONCLUSION}

In the present study, Levofloxacin has showed promising results as an analgesic when compared to the control and standard groups. It may be a lead compound for identifying newer adjuvant analgesic agents. Further studies are needed to support these findings in humans, since the animal data cannot be directly extrapolated on humans.

Funding: No funding sources Conflict of interest: None declared

Ethical approval: The study was approved by the Institutional Ethics Committee

\section{REFERENCES}

1. H. Merskey. Pain terms: a list with definitions and notes on usage. Recommended by the IASP Subcommittee on Taxonomy. Pain. 1979;6(3):249-52.

2. Fields HL, Martin JB. Pain Pathophysiology and management. In: Harrisons Principles of Internal Medicine, 17th edition, Volume I, McGraw-Hill Companies, United States of America. 2007;81-86.

3. DJ Hewitt, RJ Hargreaves, SP Curtis, D Michelson. Challenges in analgesic drug development. Clinical pharmacology \& therapeutics. 2009;86(4):447-50.

4. GR Hanson, PJ Ventrurelli, AE Fleckenstein, Jones Bartlett, Boston. Mass USA Drugs and society. 10th edition. 2009.

5. Eddy NB, Leimbach D. Synthetic analgesics. II. Dithienylbutenyl - And dithienylbutylamines. J Pharmacol Exp Ther. 1953;107(3):385-93.

6. Kulkarni SK. Handbook of Experimental Pharmacology. 3rd ed. New Delhi: Vallabh Prakashan. 1999.

7. S Higuchi, N Tanaka, Shiioiri Y, Otomos S, Aihara H. Two modes of analgesic action of aspirin, and the site of analgesic action of salicyclic acid. International Journal Of Tissue Reactions. 1986;8(4):327-31.

8. Medhi B, Prakash A, editors. Practical manual of experimental and clinical pharmacology.1st edition. New Delhi; Jaypee Publications. 2010;322-5.

9. Vogel H. H.I Central analgesic activity, In vitro methods for opioid activity. Drug Discovery and Evaluation: Pharmacological Assays. Springer-Verlag Berlin Heidelberg New York. 2007;360-65.

10. Woolfe G, MacDonald AD. The evaluation of analgesic action pethidine hydrochloride. Journal of Pharmacology and Experimental Therapeutics. 1994;80(3):300-07.

11. Yildiran G, Ulak G, GoÈldeli E, Utkan T, Gacar N, Erden BF. Antinociception induced by verapamil and chloramphenicol in mice. Biol Neonatology. 1997;72:28-31.

12. Erden BF, Ulak G, Ylldlz F, Utkan T. Antidepressant, anxiogenic and antinociceptive properties of levofloxacin in rats and mice. Pharmacology Biochemistry and Behavior. 2001;68(3):435-41.

13. Takasuna K, Kasai Y, Usui C, Takahashi M, Hirohashi M, Tamura K, Takayama S. General pharmacology of the new quinolone antibacterial agent, levofloxacin. Arzneimittel for schung. 1992;43(3A):408-18.

14. Schroeder CI, Doering CJ, Zamponi GW, Lewis RJ. $\mathrm{N}$-type calcium channel blockers: Novel therapeutics for the treatment of pain. Medicinal Chemistry. 2006;2(5):535-43.

15. Zamponi GW, Lewis RJ, Todorovic SM, Arneric SP, Snutch TP. Role of voltage-gated calcium channels in ascending pain pathways. Brain Res Rev. 2009;60(1):84-9.

16. Kerr LM, Filloux F, Olivera BM, Jackson H, Wamsley JK. Autoradiographic localization of calcium channels with [125I] omega-conotoxin in rat brain. Eur J Pharmacol. 1988;146(1):181-3. 
17. Erden BF, Ulak G, Yildiz F, Utkan T, Ozdemirci S, Gacar N. Antidepressant, anxiogenic, and antinociceptive properties of levofloxacin in rats and mice. Pharmacology, Biochemistry and Behavior. 2001;68:435-41.

18. Yaksh TL. Calcium channels as therapeutic targets in neuropathic pain. J Pain. 2006;(1):S13-30.

19. McGivern JG, McDonough SI. Voltage-gated calcium channels as targets for the treatment of chronic pain. Current Drug Targets CNS Neurological Disorders. 2004;3(6):457-78.

20. Metterlein T, Schuster F, Tadda L, Hager M, Muldoon $\mathrm{S}$, Capacchione J, et al. Fluoroquinolones influence the intracellular calcium handling in individuals susceptible to malignant hyperthermia. Muscle nerve. 2011;44(2):208-12.

21. Gohil K, Bell JR, Ramachandran J, Miljanich GP. Neuroanatomical distribution of receptors for a novel voltagesensitive calcium-channel antagonist, SNX230 (omegaconopeptide MVIIC). Brain Res. 1994;653(1-2):258-66.

Cite this article as: Prasanna KS, Latha K, Meeradevi A. Evaluation of analgesic activity of levofloxacin in adult albino rats. Int $\mathbf{J}$ Basic Clin Pharmacol 2021;10:85-9. 